\section{IGOS AND GLOBAL CLIMATE SECURITY CHALLENGES: IMPLICATIONS FOR ACADEMIC RESEARCH AND POLICYMAKING}

\author{
LISA M. DELLMUTH, MARIA-THERESE GUSTAFSSON, \\ NIKLAS BREMBERG AND MALIN MOBJÖRK*
}

\section{INTRODUCTION}

Climate change poses a new class of security challenges that is confronting societies worldwide. Increased risk of famine, destroyed infrastructure, houses and shelter, and violent conflicts might all be consequences of climate change through gradual changes to ecosystems and extreme weather events. ${ }^{1}$

As climate security challenges are typically transnational in nature, states are increasingly relying on intergovernmental organizations (IGOs)-such as the European Union (EU), the North Atlantic Treaty Organization (NATO) and the United Nations Environment Programme (UNEP)-in their responses to them. However, the growing importance of IGOs raises a number of questions. Should traditional security organizations such as NATO or the UN Security Council deal with climate change? Should the UN High Commissioner for Refugees (UNHCR) expand its work to address climate security challenges? To what degree must IGOs with mandates in different policy areas (e.g. environment, health and security) work together in order to effectively address climate change?

While IGOs are increasingly important, little is known about the conditions under which they address climate security challenges, and when they do so effectively. Over the past decade, however, research within environmental social sciences, International Relations, and political science has analysed the mandates, behaviour and case-specific effectiveness of IGOs addressing climate security challenges. This SIPRI Fact Sheet summarizes the key findings of the first systematic review of research on IGOs and climate security, and the implications of existing studies for the theory and practice of global climate security governance. ${ }^{2}$

1 For a recent overview, see Mobjörk, M. et al., Climate-related Security Risks: Towards an Integrated Approach (SIPRI and Stockholm University: Stockholm, Oct. 2016).

2 Dellmuth, L. M. et al., 'Intergovernmental organizations and climate security: Advancing the research agenda', WIREs Climate Change, 13 Oct. 2017.

* This work is funded by the Swedish Ministry for Foreign Affairs as part of its Climate Change and Security project, and the Mistra Geopolitics research programme.

\section{KEY FACTS}

- 'Climate security' refers to the condition where people, communities and states have the capacity to manage threats and risks emerging from climate change and variability.

- Over the past decade, states have delegated increased power to intergovernmental organizations (IGOs) to address climate security challenges.

- A young but burgeoning field of academic research has focused on the mandates, behaviour and effectiveness of IGOs in addressing climate security challenges.

- To improve effectiveness, policymakers should promote institutional arrangements and cooperation that include IGOs with different mandates affected by climate security challenges.

- Academic research needs to enhance knowledge about when and why IGOs address climate security challenges, and how they can do so effectively. 


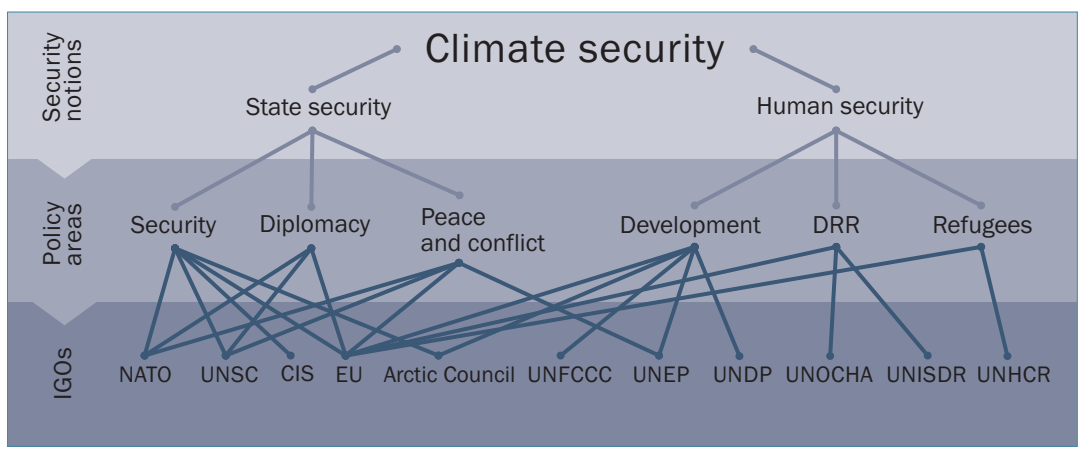

CIS = Commonwealth of Independent States; EU = European Union; NATO = North Atlantic Treaty Organization ; UNDP = United Nations Development Programme; UNEP = United Nations Environment Programme; UNFCCC = United Nations Framework Convention on Climate Change; UNHCR = United Nations High Commissioner for Refugees; UNISDR = United Nations Office for Disaster Risk Reduction; UNOCHA = United Nations Office for the Coordination of Humanitarian Affairs; UNSC = United Nations Security Council.

Figure 1. The emerging field of research on intergovernmental organizations and climate security

Source: Dellmuth, L. M. et al., 'Intergovernmental organizations and climate security: Advancing the research agenda', WIREs Climate Change, 13 Oct. 2017.

\section{IGOS AND CLIMATE SECURITY}

The emerging field of research on IGOs and climate security draws heavily on the twin concepts of state security and human security (see figure 1). In this context, state security is typically understood as the condition where states have the capacity to manage climate-related threats to safeguard their sovereignty, military strength and power in the international system; human security is commonly defined as the condition where individuals and communities have the capacity to manage, reduce or prevent sudden or chronic climate-related risks such as hunger, disease and rights violations. Bridging this distinction, 'climate security' refers to the condition where people, communities and states have the capacity to manage stress-and ultimately prevent risks-emerging from climate change and climate variability. This definition opens up an understanding of how the multifaceted impacts of climate change simultaneously affect state security and human security.

Based on different notions of security, previous research has focused on a set of policy areas. State security is the primary focus of studies on security, diplomacy, and peace and conflict; whereas human security is predominantly studied in relation to development, disaster risk reduction (DRR) and migration.

\section{THE RESPONSES OF IGOS AND THEIR EFFECTIVENESS}

Although research on IGOs and climate security is an emerging field, it is possible to distil important findings about how and why IGOs respond to climate security challenges, particularly in the context of IGOs with mandates in state security. Existing studies show two generic forms of IGO response: discourse and governance.

In terms of discourse, international policymakers increasingly frame climate change as a security issue across policy areas. Illustrative examples include: (a) NATO, which has sought to securitize climate change to safeguard its military force; (b) the EU, which has made attempts to securitize climate-induced migration; and (c) the UN Development Programme (UNDP), which has focused on the links between climate change and human security. Climate change has thus been talked about-or 'securitized'-both in connection to state security and human security. With regard to trends and patterns of IGO discourse on climate security, most of the evidence points to organizations dealing with state security-such as the EU, NATO and the UN Security Council-but some studies describe that the EU, the UNDP and the UNEP are framing climate change in terms of its consequences for human security and vulnerability. Few studies identify the mechanisms through 
which discursive framings are translated into concrete policies designed to address these issues.

IGO responses to climate security challenges are still widely understood and framed as a reaction to manage challenges in specific policy areas (e.g. security, development and migration). However, policymakers are under increasing pressure to adequately address transboundary climate security risks, facing an increased burden of proof in explaining how climate security challenges can be effectively addressed by linking governance efforts within and across policy areas.

In terms of governance (i.e. rules embodied in formal institutions and intersubjective understandings), the main IGOs studied in this body of literature are the EU, NATO, the UN Security Council and UN agencies with a mandate in environment, development and humanitarian affairs. Research has revealed that IGOs have increasingly engaged in climate security governance primarily through working groups and the assessment of climate risks-for both state security and human security.

In terms of state security, previous studies have shown that governance responses from an IGO, such as NATO, are predominantly directed at enhancing the military capacities of its member states to withstand the adverse effects of climate change through, for example, assessment exercises. Researchers have suggested that the EU is better suited to address climate security challenges due to its comprehensive approach to security, although many indicate that this potential has not been fulfilled. Research has also focused on the question of whether the the UN Security Council can address climate security within its current mandate. In the absence of a broad international agreement on climate-related effects on international security, however, the development of effective governance responses by the the UN Security Council is unlikely.

In terms of human security, most research has focused on the efforts of UN agencies to counteract the adverse effects of climate change in diverse policy areas such as development, migration and DRR. For example, the UNDP started developing governance strategies to address climate-related risks for human security in 2007. In the area of migration, the UNHCR has sought to address climate-induced displacement of people by participating for instance in the UN Framework Convention on Climate Change (UNFCCC) negotiations. However, this has not yet led to any concrete policy changes, as the issue is perceived to lie outside the UNHCR's mandate. In studies on human security, integrated governance has been discussed as a vital factor in the areas of DRR, climate change adaptation, and development for shaping the effectiveness of UN agencies. Moreover, researchers have emphasized the importance of more people-centred and rights-based approaches to climate security.

\section{IMPLICATIONS FOR FUTURE RESEARCH AND POLICY}

The review identified two main research gaps: (a) integrated governance approaches, and (b) the effectiveness of IGOs in addressing climate security challenges. Little is still known about the conditions under which IGOs engage in integrated governance, and when they do so effectively. Drawing on broader international relations literature on institutional change and 
SIPRI is an independent international institute dedicated to research into conflict, armaments, arms control and disarmament. Established in 1966, SIPRI provides data, analysis and recommendations, based on open sources, to policymakers, researchers, media and the interested public.

\section{GOVERNING BOARD}

Ambassador Jan Eliasson, Chair (Sweden)

Dr Dewi Fortuna Anwar (Indonesia)

Dr Vladimir Baranovsky (Russia)

Ambassador Lakhdar Brahimi (Algeria)

Espen Barth Eide (Norway)

Ambassador Wolfgang

Ischinger (Germany)

Dr Radha Kumar (India)

The Director

\section{DIRECTOR}

Dan Smith (United Kingdom)

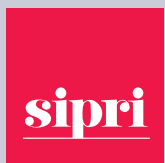

STOCKHOLM INTERNATIONAL PEACE RESEARCH INSTITUTE Signalistgatan 9 SE-169 72 Solna, Sweden Telephone: +4686559700 Email:sipri@sipri.org Internet: www.sipri.org

effectiveness can provide useful guidance in this regard. Methodologically, thinking conditionally about institutional change and effectiveness, complementing existing case study research with theory-driven comparative research is advocated. When findings converge, more general insight about the conditions for institutional change and effectiveness in global climate security governance is gained.

There are three main implications for policymakers. First, climate security challenges are becoming increasingly important in global governance, and viable and effective policy solutions are therefore needed. States will remain important players in this regard, but IGOs will need to develop their capacity to respond effectively due to the transboundary nature of the challenges.

Second, the literature indicates several ways to promote the viability and effectiveness of IGOs within climate security, given that climate security spans traditional policy areas such as development and DRR. Potential governance solutions include the establishment of working groups, the development of tools for risk assessments, and data collection on risks and existing governance responses. This should be done through including climate security risks in existing projects, sharing information, joint financing and staff training, as well as by developing new institutional arrangements that bridge silos within and across IGOs. More broadly, IGOs need to rethink how to interpret their mandates in light of emerging climate security issues, and to debate and problematize how climate change impinges on their mandates.

Third, IGOs should reflect on which governance responses lead to more effectiveness. How can effectiveness be understood and measured, given the uncertainty and long temporal scales involved in climate security challenges? How can prevention be thought about in the long run? How can institutions improve their ability to foresee climate security crises by bringing together data on multiple risks (e.g. droughts and conflicts) and existing adaptive capacity? How can IGOs support the abilities of fragile states to respond effectively climate security challenges?

To conclude, the challenge is to find ways to link knowledge about local vulnerabilities, capacities and institutions with global governance responses and opportunities for cooperation across IGOs. Exploring these linkages will be key for enhancing the responses of IGOs to climate security challenges.

\section{ABOUT THE AUTHORS}

Lisa Maria Dellmuth (Sweden) is an Associate Professor of International Relations at Stockholm University.

Niklas Bremberg (Sweden) is a Research Fellow at the Swedish Institute of International Affairs.

Maria-Therese Gustafsson (Sweden) is a Postdoctoral Research Fellow at the Department of Political Science at Stockholm University.

Malin Mobjörk (Sweden) is a Senior Researcher and Director of SIPRI's Climate Change and Risk Programme.

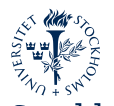

Stockholm University

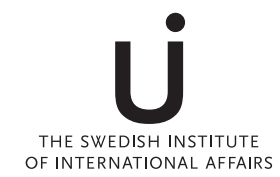

OF INTERNATIONAL AFFAIRS

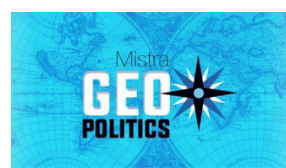

(C) SIPRI 2017 